\title{
Association between quality of life and mental stress-induced myocardial ischemia in high-risk patients after coronary revascularization
}

\section{Xiantao Song ( $\nabla$ songxiantao0929@qq.com )}

Beijing Anzhen Hospital

\section{Nan Nan}

Beijing Anzhen Hospital

\section{Wei Dong}

Beijing Anzhen Hospital

\section{Bingyu Gao}

Beijing Anzhen Hospital

\section{Feihuan Cui}

Beijing Anzhen Hospital

\section{Zhi Chang}

Beijing Anzhen Hospital

Jian Jiao

Beijing Anzhen Hospital

Huijuan Zuo

Capital Medical University, Beijing Institute of Heart Lung and Blood Vessel Disease

Hongzhi Mi

Beijing Anzhen Hospital

\section{Shuzheng Lyu}

Beijing Anzhen Hospital

Hongjia Zhang

Beijing Anzhen Hospital

\section{Research Article}

Keywords: Mental stress-induced myocardial ischemia, quality of life, Seattle Angina Questionnaire, coronary artery disease

Posted Date: January 31st, 2022

DOI: https://doi.org/10.21203/rs.3.rs-1301204/v1 
License: (c) (i) This work is licensed under a Creative Commons Attribution 4.0 International License. Read Full License 


\section{Abstract}

Objective: We sought to determine the association between mental stress-induced myocardial ischemia (MSIMI) and quality of life (QoL) in patients with coronary artery disease (CAD) after coronary revascularization.

Methods: This cohort study involved patients with high-risk MSIMI who were selected from those who received coronary revascularization between Dec 2018 and Dec 2019. Patients with screened depression/anxiety were enrolled in this study. Mental stress was induced by the Stroop Color and Word Test 4 weeks after coronary revascularization. All participants underwent single photon emission computed tomography (SPECT) scans at rest and at mental stress. MSIMI was defined as the presence of four abnormal SPECT phenomena. QoL was assessed using the Seattle Angina Questionnaire (SAQ) before and 4 weeks after coronary revascularization.

Results: Of the 1,845 consecutive patients who received coronary revascularization, 590 (31.9\%) had depression/anxiety and 205 agreed to accept the mental stress test. During the average follow-up of 42.8 days, $105(51.2 \%)$ patients developed MSIMI. All SAQ subscales were significantly improved, except for QoL, in the MSIMI group. The QoL score was lower $(-0.2 \pm 32.7$ vs. $13.1 \pm 29.9, P=0.005)$ and the proportion of deterioration in QoL was higher $(50.5 \%$ vs. $31.9 \%, P=0.010)$ in the MSIMI group than in the non-MSIMI group. Those with a deterioration in QoL were approximately two times as likely to develop MSIMI as those with the improvement in QoL (unadjusted HR: 2.019, 95\% Cl: 1.122-3.634, $P=0.026$; adjusted HR: $1.968,95 \% \mathrm{Cl}$ : $1.083-3.578, P=0.017)$.

Conclusion: Among the patients with CAD who received coronary revascularization and had depression/anxiety, deterioration in QoL increased the likelihood of MSIMI. Hence, our results indicate that deterioration in QoL is a predictor of MSIMI.

Trail Registration: ChiCTR2200055792, retrospectively registered, 2022.1.20, www.medresman.org.cn;

\section{Introduction}

Mental stress induced-myocardial ischemia (MSIMI) is defined as an imbalance between myocardial oxygen demand and supply during mental or psychological stress. Mental stress triggers transient myocardial ischemia in $30 \%-70 \%$ of patients with pre-existing coronary artery disease (CAD)[1-3] and is more common among those with depression/anxiety [4, 5]. The risk factors for MSIMI have not been clearly established, and the association between quality of life (QoL) and MSIMI has not been reported, especially in high-risk patients.

Seattle Angina Questionnaire (SAQ) is specific for CAD and has been widely accepted as a means of quantifying the outcome of CAD treatment on the patients' angina and QoL in trials[6]. SAQ measures five subscales related to CAD, namely physical limitations, angina frequency, angina stability, treatment satisfaction, and QoL. Among the MSIMI trails, only the angina-frequency subscale has been found to be 
related to MSIMI in women with stable CAD[7] and in post-myocardial-infarction patients[8]. However, a comprehensive assessment of the five SAQ subscales, especially the QoL and MSIMI, is limited.

Therefore, this study was designed to examine the association between SAQ and MSIMI in high-risk patients with stable CAD after at least 1 month of revascularization who had been screened for depression/anxiety at baseline. In addition, the association between MSIMI and the benefit or drawback of CAD revascularization assessed by SAQ was evaluated.

\section{Methods}

\section{Study Sample}

In the study of MSIMI in high-risk patients with CAD, 1,845 patients with coronary angiography-confirmed $C A D$ who received coronary revascularization treatment, including percutaneous coronary intervention (PCI) or coronary artery bypass grafting (CABG), were screened between Dec 2018 and Dec 2019. The mental health status of all patients was assessed using the nine-item Patient Health Questionnaire-9 (PHQ-9) and the seven-item Generalized Anxiety Disorder-7 (GAD-7) severity measure. Those with screened depression/anxiety (PHQ-9 $\geq 5$ and/or GAD-7 $\geq 5$ ) were enrolled in this study. The study protocol was approved by the Medical Ethics Committee of Beijing Anzhen Hospital (NO. 2019001), and all participants provided informed consent prior to inclusion in the study.

\section{Mental Stress Test}

Mental stress was induced by the Stroop Color and Word Test (SCWT), which was employed to assess the ability of inhibiting cognitive interference. The SCWT has been well-accepted for assessing patients with $C A D$ and has been shown to exhibit good reproducibility and execution $[9,10]$. A standardized computer program was used to test the participants. Four words were displayed on the computer screen (i.e., "RED," "BLUE," "GREEN," AND "YELLOW"), and the corresponding buttons were labeled with one of the four letters (i.e., "J," "K," "L," and "I"). The computer randomly assigned the four colors to these four words, and only one word appeared at a time. The participant was instructed to match the word with the corresponding button without being distracted by the color. For example, for the word "RED" presented in yellow, "J" should be selected rather than "I." If the answer was wrong, the word "ERROR" appeared on the screen, and if the participant responded too slowly, the screen displayed the words "RESPOND FASTER." During the test, an auditory stimulus was initiated by the examiners. The accuracy, response time, stimuli presentation velocity, and test duration were recorded by the computer. During the continuum of visual stimuli, a cognitive mechanism was applied to direct the attention. The procedure included: (1) the participant was informed about the testing process and underwent a practice test that lasted approximately $1 \mathrm{~min}$; and (2) the participant underwent a timed test. The SCWT lasted approximately 5 minutes. Non-invasive continuous blood pressure and heart rate measurements were performed every minute. Rate-pressure product (RPP) was calculated as systolic blood pressure (SBP) $\times$ heart rate (HR). The maximum values of SBP and HR during mental stress were selected. 


\section{Single Photon Emission Computed Tomography (SPECT) Myocardial Perfusion Imaging}

Each participant underwent electrocardiographically gated technetium-99m ( $\left.{ }^{99 \mathrm{~m}} \mathrm{Tc}\right)$-sestamibi SPECT imaging 4 weeks after PCI/CABG. All participants underwent two SPECT scans on two separate days: the first one at rest and the second one after mental stress. The patients received ${ }^{99 \mathrm{~m}} \mathrm{Tc}$-sestamibi at a dose of 20-25 mCi during the rest and stress phases. The SCWT mental stress test lasted approximately 5

minutes, and ${ }^{99 \mathrm{~m}} \mathrm{Tc}$-sestamibi was intravenously administered 1 minute after the test started. Images were acquired using an e-Cam Duet Gamma Camera (Siemens AG, Erlangen, Germany) 60-90 minutes after the intravenous administration of ${ }^{99 \mathrm{~m}} \mathrm{Tc}$-sestamibi.

The SPECT images were individually analyzed by two experienced readers blinded to patient data. The extent and severity of myocardial ischemia were assessed using a 17-segment model with Quantitative Gated SPECT software. Tridimensional reconstruction of the left ventricle was done for assessing ventricular function, in addition to the analyses of ejection fraction (EF), end-diastolic volume (EDV), endsystolic volume (ESV), contractility, and myocardial thickness[10]. Four abnormal SPECT phenomena were considered positive for MISIMI[11, 12], including reversible myocardial perfusion defects, transient ischemic dilation (TID), reverse redistribution, and EF reduction of $\geq 5 \%[13]$. Mental stress and rest images were analyzed using total perfusion deficit (TPD) $[14,15]$.

\section{Assessment of Coronary-related Quality of Life}

The 19-item SAQ questionnaire, which measures five domains related to CAD, was used to assess angina frequency, physical limitations, angina stability, treatment satisfaction, and QoL. The scores ranged from 0 to 100, with higher scores indicating fewer symptoms and a better health status[16]. The participants were evaluated using SAQ at baseline and 1 month after revascularization. Significant improvements in each subscale were predefined for physical limitation ( $\geq 8$ points), angina frequency ( $\geq 20$ points), and QoL ( $\geq 16$ points)[17].

\section{Statistical Analysis}

Continuous variables were reported as mean \pm standard deviation, and categorical variables as numbers and percentages. Concomitant medication was summarized and compared between the groups at discharge and after 1 month using the $\mathrm{c}^{2}$ test or Fisher's exact test, whichever was appropriate. Each domain of the SAQ was evaluated using analysis of covariance at baseline and at 1-month follow-up. For all other endpoints, a two-sided probability $(p)$ value of 0.05 without correction for multiple testing was considered statistically significant. Logistic regression was used to identify the factors associated with poor QoL and MSIMI. The model was adjusted for coronary risk factors and imbalance factors at baseline. 


\section{Results}

Of the 1,845 consecutive patients with CAD who received PCI/CABG, 590 (31.9\%) exhibited depression/anxiety and 205 agreed to undergo the mental stress test. The mean age of the participants was 59.72 years (standard deviation [SD], 10.1), and 64 (31.2\%) were women. The mental stress test was performed subsequent to an average follow-up of 42.8 days (SD, 46.1) after coronary revascularization.

Overall, 105 (51.2\%) patients developed MSIMI. Among them, 59 (56.2\%) had reversible myocardial perfusion defects, 30 (28.6\%) had an EF reduction of $\geq 5 \%, 27$ (25.7\%) had TID, and 13 (12.4\%) had reverse redistribution. Furthermore, 82 patients had only one abnormal phenomenon, 22 patients displayed a combination of two abnormal phenomena, and 1 patient exhibited three abnormal phenomena. The baseline characteristics of the 205 patients in the MSIMI and non-MSIMI groups are shown in Table 1. There were no significant differences between the two groups in the demographic risk factors as well as the angiographic severity of CAD. However, the MSIMI group demonstrated significantly higher PHQ9 scores at baseline, and the non-MSIMI group had a greater percentage of drinking history.

At rest, left ventricle EDV and ESV were lower in the MSIMI group than in the non-MSIMI group (79.2 \pm 30.1 vs. $92.7 \pm 44.1$ and $30.1 \pm 21.7$ vs. $40.4 \pm 34.8$, respectively, $P<0.05)$. Furthermore, EF was higher in the MSIMI group than in the non-MSIMI group ( $64.8 \pm 12.8$ vs. $60.0 \pm 12.4, P<0.01)$. On the day of the mental stress, except for the higher proportion of stress TPD in the MSIMI group, there were no significant differences in EDV, ESV, or EF between the two groups. Moreover, non-invasively measured SBP, DBP, HR, and RPP were similar between the two groups both at rest and during the mental stress test (See Table 2). None of the patients developed chest pain during the test.

The five subscales measured using the SAQ questionnaire were similar between the non-MSIMI and MSIMI groups at baseline. The only exception was physical limitations, which was statistically lower in the MSIMI group than in the non-MSIMI group ( $52.4 \pm 20.2$ vs. $58.7 \pm 17.6, P=0.025$, See Table 3$)$. During the followup at 1 month after coronary revascularization, all subscales were significantly improved in both groups ( $P$ $<0.001$ ), except for the subscale of QoL in the MSIMI group. Although the QoL improved significantly in the non-MSIMI group after coronary revascularization, the score was numerically but not statistically deteriorated in the MSIMI group (See Figure 1). Moreover, the QoL score was lower in the MSIMI group than in the non-MSIMI group at follow-up $(51.5 \pm 22.4$ vs. $58.4 \pm 22.8, P=0.031)$.

Table 4 shows the improvements in the five domains of the SAQ questionnaire. The absolute values of improvements in physical limitations, angina frequency, angina stability, and treatment satisfaction were similar between the two groups. However, the improvement value of QoL showed a significant difference between the two groups $(13.1 \pm 29.9$ vs. $-0.2 \pm 32.7, P=0.005$, See Figure 2$)$. More patients in the MSIMI group presented a significant improvement in the physical limitation subscale $(87.9 \%$ vs. $76.3 \%, P=$ 0.041 ), and fewer patients in the MSIMI group showed a significant improvement in the QoL subscale ( $31.9 \%$ vs. $50.5 \%, P=0.010)$. Overall, the QoL showed a consistently deteriorated trend in the MSIMI group but not in the non-MSIMI group. 
In this CAD associated with depression/anxiety cohort, the probability of MSIMI after 4 weeks of coronary revascularization was approximately two times in patients with deterioration in QoL than that of improvement in QoL (unadjusted hazard ratio [HR]: 2.019, 95\% confidence interval [CI]: 1.122-3.634; adjusted HR: $1.968,95 \% \mathrm{Cl}: 1.083-3.578$ ). Similarly, an improved QoL score of $<16$ was associated with a twofold increase in the probability of MSIMI when compared with a score of $\geq 16$ (unadjusted HR: 2.184, 95\% Cl: 1.199-3.979; adjusted HR: 2.105, 95\% Cl: 1.145-3.873) (See Table 5). Furthermore, a score of $<8$ in the improved subscale of physical limitations was associated with a $55.6 \%$ lower probability of MSIMI when compared with a score of $\geq 8$ (unadjusted HR: $0.444,95 \% \mathrm{Cl}$ : 0.201-0.979); however, after adjusting for the baseline factors, the association with MSIMI did not exhibit statistical significance. In addition, although the decrease in angina frequency had no association with MSIMI, after adjustment, it was associated with 2.336 times higher probability of MSIMI (adjusted HR: 2.336, 95\% Cl: 1.029-5.301). For the other two subscales, including angina stability and treatment satisfaction, the association between deterioration or no significant improvement and MSIMI had no statistical significance.

\section{Discussion}

Among the high-risk group of MSIMI, i.e., CAD with the comorbidity of depression/anxiety, coronary revascularization significantly improved physical limitations, angina frequency, angina stability, and treatment satisfaction but not QoL. The deterioration in QoL 4 weeks after coronary revascularization was associated with a twofold increase in the risk of MSIMI. These findings were independent of traditional CAD risk factors and psychological factors.

Coronary revascularization, including $\mathrm{PCl}$ and $\mathrm{CABG}$, has been proven to improve CAD-related SAQ scores in multiple populations. Our findings are consistent with this observation, except for QoL. Among patients with stable CAD in the COURAGE study[18], SAQ was used to dynamically assess the QoL after PCl or optimal medical treatment (OMT). Greatest improvements were seen in the first 3 months, especially in the three subscales of physical limitations, angina frequency, and QoL. Among the patients with chronic coronary total occlusion lesions in the EUROCTO study[17], a greater improvement in the SAQ subscales was observed with $\mathrm{PCl}$ than with OMT for angina frequency and QoL. In a large sample of 3392 patients with $C A D$, coronary revascularization, regardless of the approach being $\mathrm{PCl}$ or $\mathrm{CABG}$, was consistently associated with a significantly higher QoL, as assessed with SAQ at one-year follow-up, when compared with medical therapy[19]. In our study cohort of patients with CAD and depression/anxiety, the QoL improved in the non-MSIMI but deteriorated in the MSIMI 1 month after PCI or CABG. These findings indicate that MSIMI may weaken the beneficial effect of coronary revascularization on QoL.

In the field of MSIMI, only two studies have so far employed the SAQ to evaluate the relationship between CAD and MSIMI. In 950 patients with stable CAD, SAQ's angina-frequency subscale was used to assess the probability of developing MSIMI. Overall, 338 individuals (37\%) reported angina. It was found that only women who reported angina developed MSIMI[7]. In our study, $47.3 \%$ of the patients reported angina, which is higher than that observed in the abovementioned study, but the decrease in angina frequency had only a weak association with MSIMI. This phenomenon could probably be attributed to the differences in 
the enrollment of the participants. In our study, we considered depression/anxiety to be a high risk factor for MSIMI that would interfere with the results $[4,20,21]$. Therefore, we enrolled patients with depression/anxiety. Previous studies have recorded that patients with depression who underwent revascularization demonstrated a lower improvement in angina frequency than those without depressive symptoms[22]. Consistent with our findings, another study involving 98 post-myocardial-infarction patients found that the angina-frequency score was positively associated with MSIMI after adjusting for depressive and anxiety symptoms[8]. However, neither study comprehensively evaluated the five-subscale of SAQ. So far, there has been no study on SAQ QoL and MSIMI.

The SAQ scores have been reported to be independently associated with 1-year cardiovascular events among patients with CAD and predict 1-year mortality and cardiac rehospitalizations[23, 24]. The deterioration in QoL might be related to many factors. Depression may lead to a decline in QoL [25]. Besides, depressive symptoms may aggravate the perception of chest pain and result in a worse QoL [22, 26]. Although cognitive behavioral therapy[22] or slow breathing therapy[27] appears to have at least a modest benefit in improving the QoL, studies examining antidepressant therapies have been inconclusive.

The main strength of our study is the selection of patients with a high risk for MSIMI. Previous studies have shown that depression/anxiety may be a risk factor for MSIMI[4, 20, 21]. Thus, we selected CAD with depression/anxiety as the inclusion criterion to eliminate the influence of emotional factors on the results to the best possible extent. Furthermore, in previous MSIMI studies[7, 8, 28-30], CAD has mostly been determined based on medical history or self-reporting. However, all participants in our study were confirmed to have CAD via coronary angiography, which is more accurate than the methods used in previous studies. Moreover, considering that endothelial function and coronary microvascular disorders are possible mechanisms of MSIMI[31], except for myocardial perfusion defects, we selected TID, reverse redistribution, and EF reduction of $\geq 5 \%$, which reflected microvascular disorders[11]. Also, we specifically evaluated the relationship between MSIMI and ischemia-related vessels by analyzing the coronary angiography and SPECT images.

One of the key limitations of our study is the short follow-up period. The average follow-up time was only 42.8 days. In the future, we planned to follow up SAQ at 3 months, 6 months, and 12 months to dynamically evaluate the association with MSIMI. Besides, we did not include the effects of MSIMI and major adverse cardiovascular events. In the future, we intend to follow-up on the events using repeat coronary angiography and psychological stress test at 12 months.

\section{Conclusion}

To the best of our knowledge, this is the first study demonstrating that deterioration in CAD-related QoL is associated with an increased likelihood of MSIMI among patients with CAD and depression/anxiety. Our results highlight the relationship of QoL and the development of MSIMI.

\section{Abbreviations}


MSIMI: Mental Stress-induced Myocardial Ischemia; QoL: Quality of Life; CAD: Coronary Artery Disease; SAQ: Seattle Angina Questionnaire; SPECT: Single Photon Emission Computed Tomography; HR: Hazard Ratio; Cl: Confidence Interval; PCl: Percutaneous Coronary Intervention; CABG: Coronary Artery Bypass Grafting; PHQ9: Patient Health Questionnaire 9; GAD7: Generalized Anxiety Disorder 7; SCWT: Stroop Color and Word Test; RPP: Rate-Pressure Product; SBP: Systolic Blood Pressure; DBP: Diastolic Blood Pressure; HR: Heart Rate; EF: Ejection Fraction; LVEF: Left Ventricular Ejection Fraction; EDV: End-Diastolic Volume; ESV: End-Systolic Volume; TID: Transient Ischemic Dilation; TPD: Total Perfusion Deficit; SYNTAX: Synergy between PCI with Taxus and Cardiac Surgery; BL: Baseline; FU: Follow-Up; OMT: Optimal Medical Treatment;

\section{Declarations}

\section{Ethics approval and consent to participate}

The study protocol was approved by the Medical Ethics Committee of Beijing Anzhen Hospital (NO. 2019001), and all participants provided informed consent prior to inclusion in the study.

\section{Consent for publication}

Not applicable.

\section{Availability of data and materials}

The datasets analyzed during the current study are not publicly available because the data are guaranteed to be confidential.

\section{Competing interests}

The authors declare that they have no competing interests.

\section{Funding}

Dr. Xiantao Song received a grant from China Cardiovascular Disease Alliance VG Youth Fund Project. This study was funded by the China Cardiovascular Disease Alliance VG Youth Fund Project (Grant No. 2017CCA-VG-007) and the Beijing Lab for Cardiovascular Precision Medicine (Grant No. PXM2020_014226_000017_00377132_FCG)

\section{Authors' contributions}


SXT and LVZ: Concept, study design and manuscript revision. ZHJ: Definition of intellectual content and departmental cooperation. NN: Data collection, analysis and interpretation, manuscript drafting and revision. DW, CZ, JJ and MHZ: Study design of Nuclear Medicine section, image acquisition and image data analysis. CFH: Psychological stress test and data analysis. GBY: Data acquisition and data analysis. $\mathrm{ZHJ}$ : Data analysis and statistical analysis. All authors read and approved the final manuscript.

\section{Acknowledgments}

The authors would like to thank Dr. Lu Han, Medical Research Center of Beijing Chaoyang Hospital affiliated to Capital Medical University, for his contributions toward the sample preservation in this MSIMI cohort study.

\section{References}

1. Jiang W, Samad Z, Boyle S, Becker RC, Williams R, Kuhn C, et al. Prevalence and clinical characteristics of mental stress-induced myocardial ischemia in patients with coronary heart disease. Journal of the American College of Cardiology. 2013;61:714-22.

2. Arri SS, Ryan M, Redwood SR, Marber MS. Mental stress-induced myocardial ischaemia. Heart. 2016;102:472-80.

3. Krantz DS, Sheps DS, Carney RM, Natelson BH. Effects of mental stress in patients with coronary artery disease: evidence and clinical implications. Jama. 2000;283:1800-2.

4. Zhang LJ, He DF, Yang Y, Pu LH, Xu LY, Zhou YX et al. [A clinical study of mental stress-induced myocardial ischemia in patients with stable coronary artery disease and depression/anxiety]. Zhonghua nei ke za zhi. 2018;57:494-499.

5. Jiang W. Impacts of depression and emotional distress on cardiac disease. Cleveland Clinic journal of medicine. 2008;75 Suppl 2:S20-5.

6. Spertus JA, Arnold SV. The Evolution of Patient-Reported Outcomes in Clinical Trials and Management of Patients With Coronary Artery Disease: 20 Years With the Seattle Angina Questionnaire. JAMA cardiology. 2018;3:1035-1036.

7. Pimple P, Hammadah M, Wilmot K, Ramadan R, Al Mheid I, Levantsevych O, et al. Chest Pain and Mental Stress-Induced Myocardial Ischemia: Sex Differences. The American journal of medicine. 2018;131:540-547 e1.

8. Pimple P, Shah AJ, Rooks C, Douglas Bremner J, Nye J, Ibeanu I, et al. Angina and mental stressinduced myocardial ischemia. Journal of psychosomatic research. 2015;78:433-7.

9. Rozanski A, Bairey CN, Krantz DS, Friedman J, Resser KJ, Morell M, et al. Mental stress and the induction of silent myocardial ischemia in patients with coronary artery disease. The New England journal of medicine. 1988;318:1005-12.

10. Barbirato GB, Felix R, de Azevedo JC, Correa PL, de Nobrega AC, Coimbra A, et al. Prevalence of induced ischemia by mental distress. Arquivos brasileiros de cardiologia. 2010;94:301-7, 321-7. 
11. Dorbala S, Ananthasubramaniam K, Armstrong IS, Chareonthaitawee P, DePuey EG, Einstein AJ, et al. Single Photon Emission Computed Tomography (SPECT) Myocardial Perfusion Imaging Guidelines: Instrumentation, Acquisition, Processing, and Interpretation. Journal of nuclear cardiology : official publication of the American Society of Nuclear Cardiology. 2018;25:1784-1846.

12. Becker LC, Pepine CJ, Bonsall R, Cohen JD, Goldberg AD, Coghlan C, et al. Left ventricular, peripheral vascular, and neurohumoral responses to mental stress in normal middle-aged men and women. Reference Group for the Psychophysiological Investigations of Myocardial Ischemia (PIMI) Study. Circulation. 1996;94:2768-77.

13. Jiang W. Emotional triggering of cardiac dysfunction: the present and future. Current cardiology reports. 2015;17:91.

14. Slomka PJ, Nishina H, Berman DS, Akincioglu C, Abidov A, Friedman JD, et al. Automated quantification of myocardial perfusion SPECT using simplified normal limits. Journal of nuclear cardiology : official publication of the American Society of Nuclear Cardiology. 2005;12:66-77.

15. Nakazato R, Tamarappoo BK, Kang X, Wolak A, Kite F, Hayes SW, et al. Quantitative upright-supine high-speed SPECT myocardial perfusion imaging for detection of coronary artery disease: correlation with invasive coronary angiography. Journal of nuclear medicine : official publication, Society of Nuclear Medicine. 2010;51:1724-31.

16. Spertus JA, Winder JA, Dewhurst TA, Deyo RA, Prodzinski J, McDonell M et al. Development and evaluation of the Seattle Angina Questionnaire: a new functional status measure for coronary artery disease. Journal of the American College of Cardiology. 1995;25:333-41.

17. Werner GS, Martin-Yuste V, Hildick-Smith D, Boudou N, Sianos G, Gelev V, et al. A randomized multicentre trial to compare revascularization with optimal medical therapy for the treatment of chronic total coronary occlusions. European heart journal. 2018;39:2484-2493.

18. Weintraub WS, Spertus JA, Kolm P, Maron DJ, Zhang Z, Jurkovitz C, et al. Effect of PCl on quality of life in patients with stable coronary disease. The New England journal of medicine. 2008;359:677-87.

19. Norris CM, Saunders LD, Ghali WA, Brant R, Galbraith PD, Graham M, et al. Health-related quality of life outcomes of patients with coronary artery disease treated with cardiac surgery, percutaneous coronary intervention or medical management. The Canadian journal of cardiology. 2004;20:1259-66.

20. Wei J, Pimple P, Shah AJ, Rooks C, Bremner JD, Nye JA, et al. Depressive symptoms are associated with mental stress-induced myocardial ischemia after acute myocardial infarction. PloS one. 2014;9:e102986.

21. Boyle SH, Samad Z, Becker RC, Williams R, Kuhn C, Ortel TL, et al. Depressive symptoms and mental stress-induced myocardial ischemia in patients with coronary heart disease. Psychosomatic medicine. 2013;75:822-31.

22. Hayek SS, Ko YA, Awad M, Del Mar Soto A, Ahmed H, Patel K, et al. Depression and chest pain in patients with coronary artery disease. International journal of cardiology. 2017;230:420-426.

23. Spertus JA, Jones P, McDonell M, Fan V, Fihn SD. Health status predicts long-term outcome in outpatients with coronary disease. Circulation. 2002;106:43-9. 
24. Patel KK, Arnold SV, Chan PS, Tang Y, Jones PG, Guo J, et al. Validation of the Seattle angina questionnaire in women with ischemic heart disease. American heart journal. 2018;201:117-123.

25. Bishawi M, Hattler B, Almassi GH, Spertus JA, Quin JA, Collins JF, et al. Preoperative factors associated with worsening in health-related quality of life following coronary artery bypass grafting in the Randomized On/Off Bypass (ROOBY) trial. American heart journal. 2018;198:33-38.

26. Calvo-Perxas L, Vilalta-Franch J, Turro-Garriga O, Lopez-Pousa S, Garre-Olmo J. Gender differences in depression and pain: A two year follow-up study of the Survey of Health, Ageing and Retirement in Europe. Journal of affective disorders. 2016;193:157-64.

27. Lachowska K, Bellwon J, Morys J, Gruchala M, Hering D. Slow breathing improves cardiovascular reactivity to mental stress and health-related quality of life in heart failure patients with reduced ejection fraction. Cardiology journal. 2020;27:772-779.

28. Hassan M, York KM, Li H, Li Q, Sheps DS. Mental stress-induced myocardial ischemia in coronary artery disease patients with left ventricular dysfunction. Journal of nuclear cardiology: official publication of the American Society of Nuclear Cardiology. 2007;14:308-13.

29. Hammadah M, Al Mheid I, Wilmot K, Ramadan R, Shah AJ, Sun Y, et al. The Mental Stress Ischemia Prognosis Study: Objectives, Study Design, and Prevalence of Inducible Ischemia. Psychosomatic medicine. 2017;79:311-317.

30. Goldberg AD, Becker LC, Bonsall R, Cohen JD, Ketterer MW, Kaufman PG, et al. Ischemic, hemodynamic, and neurohormonal responses to mental and exercise stress. Experience from the Psychophysiological Investigations of Myocardial Ischemia Study (PIMI). Circulation. 1996;94:2402-9.

31. Meadows JL, Shah S, Burg MM, Pfau S, Soufer R. The Foundational Role of Cardiovascular Imaging in the Characterization of Mental Stress-Induced Myocardial Ischemia in Patients with Coronary Artery Disease. Current cardiology reports. 2020;22:162.

\section{Tables}

Table 1

The baseline characteristics of the MSIMI and non-MSIMI groups 


\begin{tabular}{|lllll|}
\hline & Non-MSIMI & MSIMI & Statistics & $P$ \\
\hline N & 100 & $105(51.2)$ & & \\
\hline Age (years) & $59.3 \pm 10.0$ & $60.2 \pm 10.1$ & $\mathrm{t}=0.626$ & 0.532 \\
\hline Sex [female (\%)] & $25(25.0)$ & $39(37.1)$ & $\chi^{2}=3.517$ & 0.061 \\
\hline Hypertension (\%) & $63(63.0)$ & $72(68.6)$ & $\chi^{2}=0.707$ & 0.400 \\
\hline Hyperlipidemia (\%) & $59(59.0)$ & $65(61.9)$ & $\chi^{2}=0.181$ & 0.671 \\
\hline Diabetes (\%) & $40(40.0)$ & $31(29.5)$ & $\chi^{2}=2.483$ & 0.115 \\
\hline Depression (\%) & $6(6.0)$ & $6(5.7)$ & $\chi^{2}=0.008$ & 0.931 \\
\hline Current smoking (\%) & $38(38.0)$ & $32(30.5)$ & $\chi^{2}=1.289$ & 0.256 \\
\hline Smoking history (\%) & $60(60.0)$ & $57(54.3)$ & $\chi^{2}=0.683$ & 0.409 \\
\hline Drinking history (\%) & $55(55.0)$ & $40(38.1)$ & $\chi^{2}=5.886$ & 0.015 \\
\hline Family history of CAD (\%) & $30(30.0)$ & $23(21.9)$ & $\chi^{2}=1.751$ & 0.186 \\
\hline Onset time (\%) & $32.3 \pm 58.1$ & $46.0 \pm 65.9$ & $\mathrm{t}=1.574$ & 0.117 \\
\hline Number of events & $0.5 \pm 0.9$ & $0.6 \pm 0.9$ & $\mathrm{t}=0.737$ & 0.462 \\
\hline SYNTAX score & $20.2 \pm 14.3$ & $20.9 \pm 12.6$ & $\mathrm{t}=0.352$ & 0.725 \\
\hline Residual SYNTAX & $3.5 \pm 7.9$ & $4.9 \pm 9.2$ & $\mathrm{t}=1.229$ & 0.220 \\
\hline Number of diseased blood vessels & $1.9 \pm 1.0$ & $2.0 \pm 1.0$ & $\mathrm{t}=0.373$ & 0.709 \\
\hline PHQ9 baseline & $6.6 \pm 3.1$ & $7.9 \pm 4.3$ & $\mathrm{t}=2.368$ & 0.019 \\
\hline GAD7 baseline & $5.1 \pm 4.3$ & $6.1 \pm 5.0$ & $\mathrm{t}=1.511$ & 0.132 \\
\hline PHQ9 follow-up & $3.7 \pm 3.3$ & $3.7 \pm 3.3$ & $\mathrm{t}=0.071$ & 0.943 \\
\hline GAD7 follow-up & $2.4 \pm 3.0$ & $2.3 \pm 2.5$ & $\mathrm{t}=0.394$ & 0.694 \\
\hline
\end{tabular}

MSIMI: mental stress-induced myocardial ischemia; CAD: coronary artery disease; PHQ9: Patient Health Questionnaire-9; GAD7: Generalized Anxiety Disorder-7; SYNTAX: Synergy between PCI with Taxus and Cardiac Surgery

Table 2

Differences in the indexes between the non-MSIMI and MSIMI groups before and after the mental stress 


\begin{tabular}{|lllll|}
\hline & Non-MSIMI & MSIMI & Statistics & $P$ \\
\hline Number & 100 & $105(51.2)$ & & \\
\hline Rest Status & & & & \\
\hline Rest TPD $(\%)$ & $4.9 \pm 11.0$ & $4.12 \pm 9.4$ & $\mathrm{t}=0.551$ & 0.582 \\
\hline Rest EDV $(\mathrm{ml})$ & $92.7 \pm 44.1$ & $79.2 \pm 30.1$ & $\mathrm{t}=2.577$ & 0.011 \\
\hline Rest ESV $(\mathrm{ml})$ & $40.4 \pm 34.8$ & $30.1 \pm 21.7$ & $\mathrm{t}=2.517$ & 0.013 \\
\hline Rest LVEF $(\%)$ & $60.0 \pm 12.4$ & $64.8 \pm 12.8$ & $\mathrm{t}=2.707$ & 0.007 \\
\hline Rest SBP $(\mathrm{mmHg})$ & $128.7 \pm 16.7$ & $131.4 \pm 18.2$ & $\mathrm{t}=1.083$ & 0.280 \\
\hline Rest DBP $(\mathrm{mmHg})$ & $80.1 \pm 11.0$ & $78.2 \pm 10.3$ & $\mathrm{t}=1.262$ & 0.208 \\
\hline Rest HR $(\mathrm{bpm})$ & $71.1 \pm 10.8$ & $69.8 \pm 12.7$ & $\mathrm{t}=0.791$ & 0.430 \\
\hline Mental Stress status & & & & \\
\hline Stress TPD $(\%)$ & $4.8 \pm 11.0$ & $7.7 \pm 9.8$ & $\mathrm{t}=1.988$ & 0.048 \\
\hline Stress EDV $(\mathrm{ml})$ & $91.3 \pm 42.2$ & $82.4 \pm 29.2$ & $\mathrm{t}=1.746$ & 0.082 \\
\hline Stress ESV $(\mathrm{ml})$ & $38.2 \pm 34.9$ & $31.7 \pm 21.6$ & $\mathrm{t}=1.588$ & 0.114 \\
\hline Stress LVEF $(\%)$ & $62.4 \pm 13.2$ & $64.1 \pm 12.0$ & $\mathrm{t}=0.950$ & 0.343 \\
\hline Stress max SBP $(\mathrm{mmHg})$ & $149.7 \pm 18.7$ & $150.4 \pm 20.0$ & $\mathrm{t}=0.273$ & 0.785 \\
\hline Stress max DBP (mmHg) & $90.2 \pm 12.3$ & $88.1 \pm 11.0$ & $\mathrm{t}=1.293$ & 0.198 \\
\hline Stress max HR (bpm) & $76.7 \pm 12.6$ & $74.1 \pm 13.7$ & $\mathrm{t}=1.362$ & 0.175 \\
\hline RPP & $11518.4 \pm 2709.1$ & $11150.0 \pm 2528.3$ & $\mathrm{t}=1.007$ & 0.315 \\
\hline
\end{tabular}

MSIMI: mental stress-induced myocardial ischemia; TPD: total perfusion deficit; EDV: end-diastolic volume; ESV: end-systolic volume; LVEF: left ventricular ejection fraction; SBP: systolic blood pressure; DBP: diastolic blood pressure; HR: heart rate; RPP: rate-pressure product

Table 3

Five domains of SAQ before and 1 month after coronary revascularization in the non-MSIMI and MSIMI groups 


\begin{tabular}{|c|c|c|c|c|c|c|c|c|}
\hline & \multicolumn{3}{|c|}{ Non-MSIMI $(n=100)$} & \multicolumn{3}{|c|}{$\operatorname{MSIMI}(\mathrm{n}=105)$} & \multicolumn{2}{|l|}{$P$} \\
\hline & $B L$ & FU & $P$ & $B L$ & FU & $P$ & $\begin{array}{l}\text { BL- } \\
\text { BL }\end{array}$ & $\begin{array}{l}\text { FU- } \\
\text { FU }\end{array}$ \\
\hline $\begin{array}{l}\text { Physical } \\
\text { limitations }\end{array}$ & $58.7 \pm 17.6$ & $83.8 \pm 9.1$ & $\hat{0} .001$ & $52.4 \pm 20.2$ & $81.4 \pm 12.0$ & $<.001$ & 0.025 & 0.110 \\
\hline $\begin{array}{l}\text { Angina } \\
\text { frequency }\end{array}$ & $29.0 \pm 26.9$ & $84.3 \pm 24.5$ & $\begin{array}{l}<.001 \\
0.001\end{array}$ & $30.2 \pm 32.8$ & $81.2 \pm 24.5$ & $\begin{array}{l}<.001 \\
0.00\end{array}$ & 0.788 & 0.372 \\
\hline $\begin{array}{l}\text { Angina } \\
\text { stability }\end{array}$ & $60.1 \pm 29.2$ & $90.9 \pm 15.1$ & $\begin{array}{l}<.001 \\
0.001\end{array}$ & $58.2 \pm 28.9$ & $87.9 \pm 17.4$ & $<.001$ & 0.663 & 0.139 \\
\hline $\begin{array}{l}\text { Treatment } \\
\text { satisfaction }\end{array}$ & $73.6 \pm 35.7$ & $89.3 \pm 32.7$ & $<.001$ & $70.0 \pm 17.0$ & $84.2 \pm 13.2$ & $<.001$ & 0.383 & 0.145 \\
\hline $\begin{array}{l}\text { Quality of } \\
\text { life }\end{array}$ & $46.7 \pm 22.5$ & $58.4 \pm 22.8$ & $\begin{array}{l}<.001 \\
0.001\end{array}$ & $53.6 \pm 23.7$ & $51.5 \pm 22.4$ & 0.939 & 0.087 & 0.031 \\
\hline
\end{tabular}

BL: baseline; FU: follow-up; SAQ: Seattle Angina Questionnaire; MSIMI: mental stress-induced myocardial ischemia

Table 4

Association between improvement in SAQ and MSIMI 


\begin{tabular}{|lllll|}
\hline & Non-MSIMI & MSIMI & Statistics & $P$ \\
\hline Physical limitations & & & \\
\hline Improvement value & $25.4 \pm 21.0$ & $30.7 \pm 20.7$ & $\mathrm{t}=1.725$ & 0.086 \\
\hline Has been Improved & $83(89.2)$ & $86(94.5)$ & $\chi^{2}=1.698$ & 0.192 \\
\hline Improved $\geq 8$ & $71(76.3)$ & $80(87.9)$ & $\chi^{2}=4.182$ & 0.041 \\
\hline Angina Frequency & & & & \\
\hline Improvement value & $55.9 \pm 34.5$ & $52.2 \pm 40.6$ & $\mathrm{t}=0.670$ & 0.504 \\
\hline Has been Improved & $82(88.2)$ & $71(78.0)$ & $\chi^{2}=3.382$ & 0.066 \\
\hline Improved $\geq 20$ & $82(88.2)$ & $71(78.0)$ & $\chi^{2}=3.382$ & 0.066 \\
\hline Angina Stability & & & & \\
\hline Improvement value & $30.3 \pm 32.1$ & $30.1 \pm 32.5$ & $\mathrm{t}=0.045$ & 0.964 \\
\hline Has been Improved & $70(75.3)$ & $69(75.8)$ & $\chi^{2}=0.008$ & 0.930 \\
\hline Freedom from Angina & $57(61.3)$ & $51(56.0)$ & $\chi^{2}=0.522$ & 0.470 \\
\hline Treatment Satisfaction & & & & 0.019 \\
\hline Improvement value & $16.8 \pm 49.9$ & $15.7 \pm 20.0$ & $\mathrm{t}=0.190$ & 0.849 \\
\hline Has been Improved & $69(74.2)$ & $65(71.4)$ & $\chi^{2}=0.178$ & 0.673 \\
\hline Quality of Life & & & & 0.010 \\
\hline Improvement value & $13.1 \pm 29.9$ & $-0.2 \pm 32.7$ & $\mathrm{t}=2.863$ & $\mathbf{0}$ \\
\hline Has been Improved & $57(61.3)$ & $40(44.0)$ & $\chi^{2}=5.545$ & $\mathbf{0}$ \\
\hline Improved $\geq 16$ & $47(50.5)$ & $29(31.9)$ & $\chi^{2}=6.613$ & 0.019 \\
\hline SAQ: Seattle Angina Questionnaire; MSIMI: mental stress-induced myocardial ischemia. & \\
\hline & & & & \\
\hline
\end{tabular}

Table 5

The association between deterioration or no significant improvement in subscales of SAQ and MSIMI 


\begin{tabular}{|c|c|c|c|c|}
\hline & Unadjusted HR & $P$ & Adjusted HR ${ }^{f}$ & $P$ \\
\hline \multicolumn{5}{|l|}{ Physical limitations } \\
\hline Deterioration $^{a}$ & $0.483[0.158-1.472]$ & 0.200 & $0.453[0.145-1.420]$ & 0.174 \\
\hline Improved < $<$ b & $0.444[0.201-0.979]$ & 0.044 & $1.080[0.992-1.175]$ & 0.075 \\
\hline \multicolumn{5}{|l|}{ Angina Frequency } \\
\hline Deterioration $^{a}$ & $2.100[0.942-4.680]$ & 0.070 & $2.336[1.029-5.301]$ & 0.048 \\
\hline Improved $<20^{c}$ & $2.100[0.942-4.680]$ & 0.070 & $1.078[0.989-1.175]$ & 0.086 \\
\hline \multicolumn{5}{|l|}{ Angina Stability } \\
\hline Deterioration $^{a}$ & $0.970[0.495-1.901]$ & 0.930 & $0.898[0.450-1.791]$ & 0.760 \\
\hline SAQ3 FU score $<100^{d}$ & $0.805[0.447-1.449]$ & 0.470 & $1.073[0.986-1.167]$ & 0.103 \\
\hline \multicolumn{5}{|l|}{ Treatment Satisfaction } \\
\hline Deterioration $^{a}$ & $1.150[0.600-2.203]$ & 0.673 & $1.127[0.581-2.188]$ & 0.723 \\
\hline \multicolumn{5}{|l|}{ Quality of Life } \\
\hline Deterioration $^{a}$ & $2.019[1.122-3.634]$ & 0.019 & $1.968[1.083-3.578]$ & 0.026 \\
\hline Improved $<16^{\mathrm{e}}$ & $2.184[1.199-3.979]$ & 0.011 & $2.105[1.145-3.873]$ & 0.017 \\
\hline \multicolumn{5}{|c|}{${ }^{a}$ Deterioration vs. improvement in SAQ during the past 4 weeks } \\
\hline \multicolumn{5}{|c|}{ b Improvement in physical limitations of $<8$ vs. significant improvement of $\geq 8$} \\
\hline \multicolumn{5}{|c|}{ c Improvement in angina frequency of $<20$ vs. significant improvement of $\geq 20$} \\
\hline \multicolumn{5}{|c|}{ d SAQ3 FU score of $<100$, denoting angina in the past 4 weeks, vs. freedom from angina } \\
\hline \multicolumn{5}{|c|}{ e Improvement in quality of life of $<16$ vs. significant improvement of $\geq 16$} \\
\hline \multicolumn{5}{|c|}{${ }^{\mathrm{f}}$ Adjusted for drinking history, PHQ9 baseline, rest EDV, rest ESV, and rest LVEF } \\
\hline \multicolumn{5}{|c|}{$\begin{array}{l}\text { SAQ: Seattle Angina Questionnaire; MSIMI: Mental Stress-induced Myocardial Ischemia; } \\
\text { HR: Hazard Ratio; FU: Follow-Up. }\end{array}$} \\
\hline
\end{tabular}

\section{Figures}




\section{The Chage of SAQ before and after 1-month of coronary revascularization in non-MSIMI and MSIMI groups}

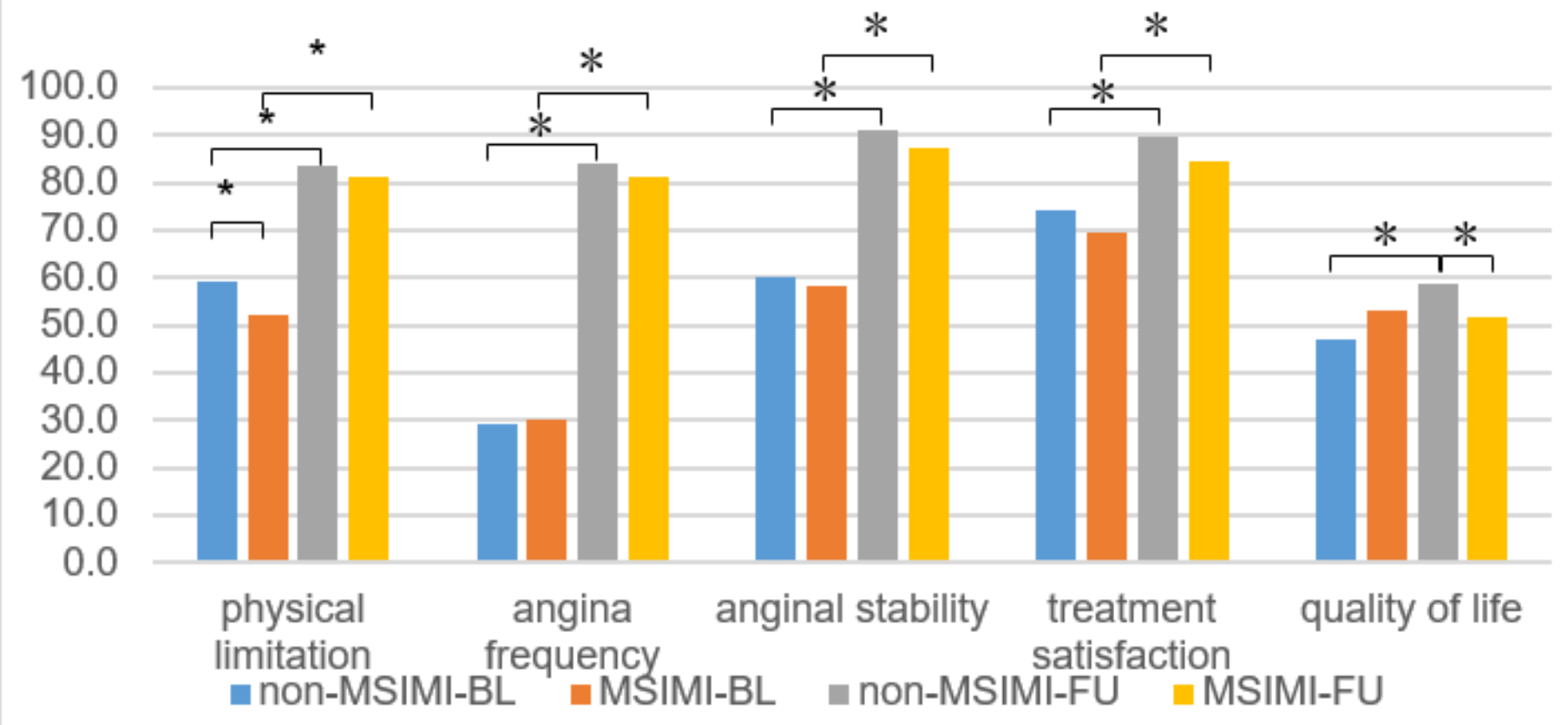

\section{Figure 1}

The change in SAQ before and after coronary revascularization in the non-MSIMI and MSIMI groups $\left({ }^{\star} P<\right.$ 0.05) 


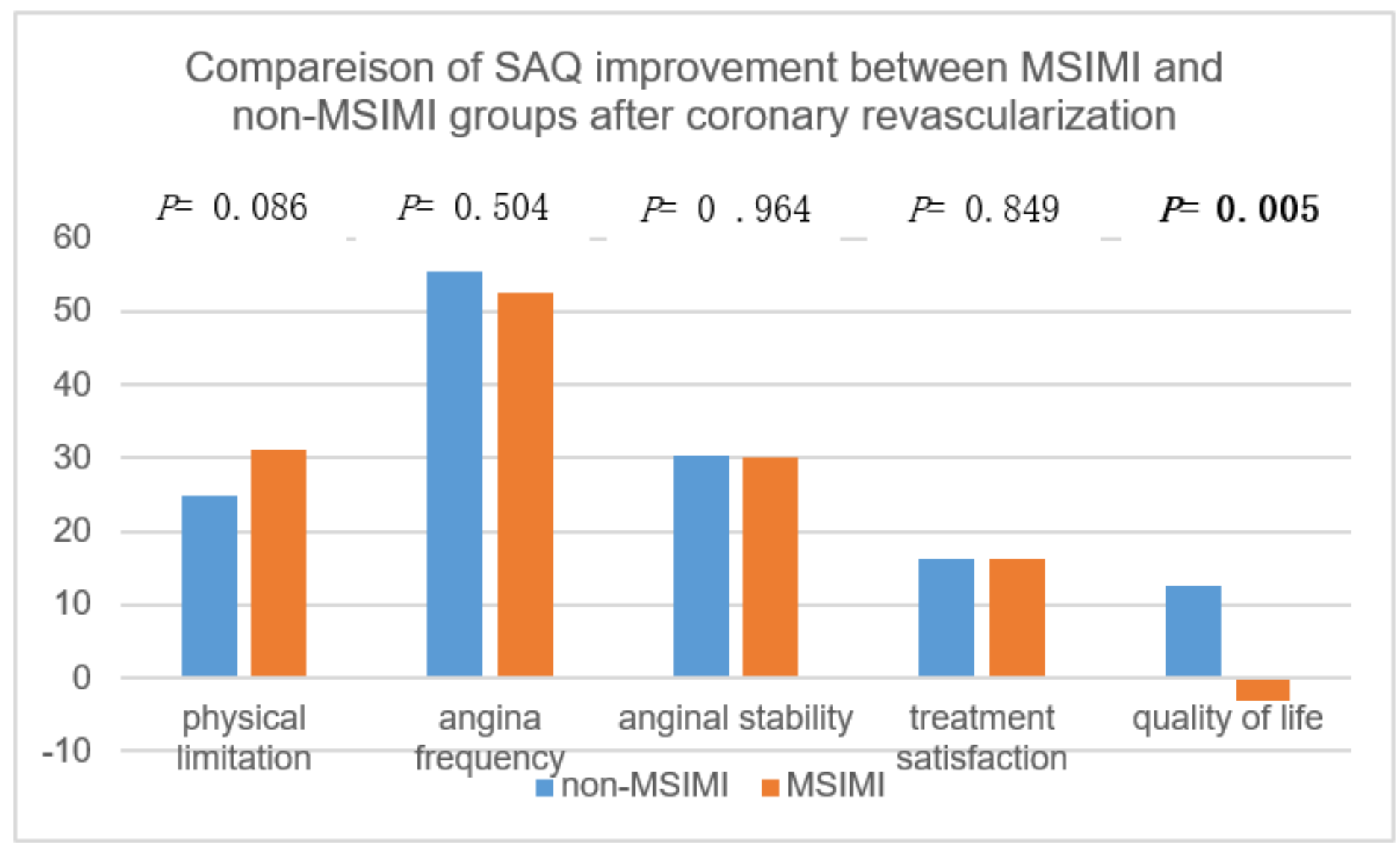

Figure 2 